\title{
Portrayal Of Violence Against Women On Media
}

\author{
Lubna Naz Karim \\ Department of Mass Communication \\ University of Karachi
}

\begin{abstract}
This study will review the role of media in portraying women and prevalence of violence in various forms like verbal, psychological, physical and symbolic against them. Technology has made media a powerful tool of communication, as well as a motivating force. Media directly or indirectly affects the minds of masses. The role of media in a society is incredible and unmatchable because the society depends on media for various reasons. This dependence on media is not only personal but social as well and it plays an important role in political, social, educational, religious and family institution at societal level. It is very much responsible for the transference of moral and social heritage from generation to generation, imposing even greater effects on the lives of ordinary citizens.

Media claims to provide the masses with knowledge and information through entertainment programs. However, portrayal of violence against women on media in the form of different characters is contrary to ethical policies. Woman is an integral part of human society. She is a source of peace and contentment not only the whole family but for society on the whole.

This study will explore that through entertainment; the negative feelings are induced into audience regarding violence against women, and where as mass media can play a significant role in reflecting social realities.
\end{abstract}

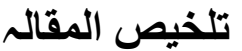

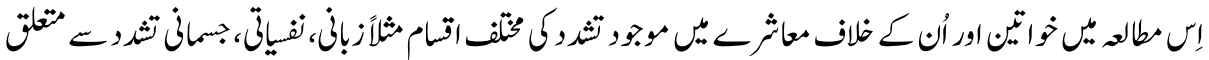

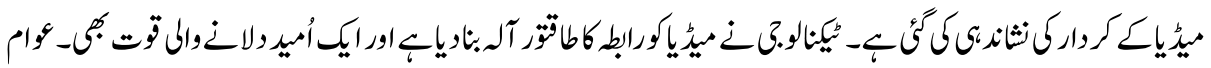

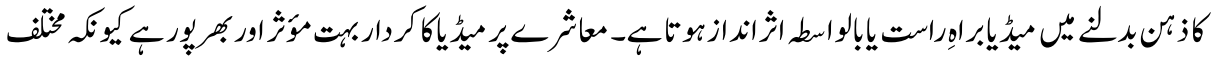

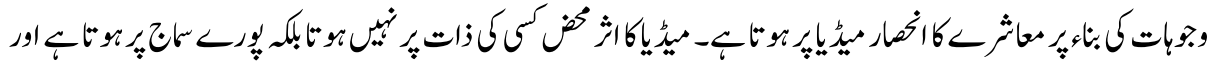

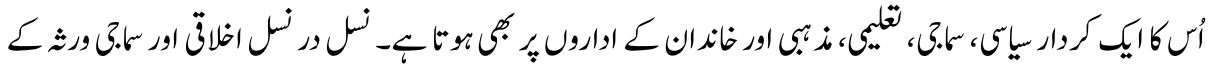

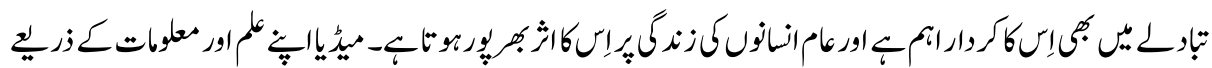

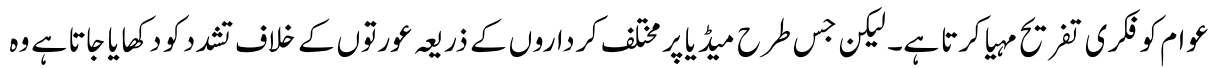

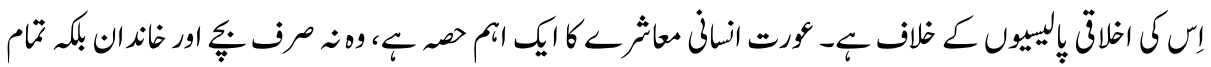

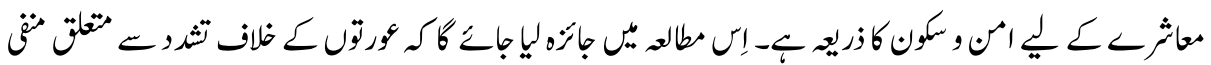

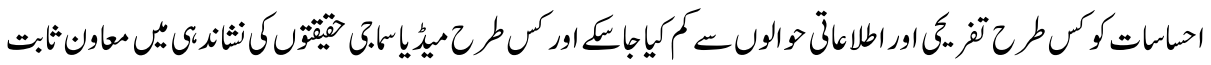

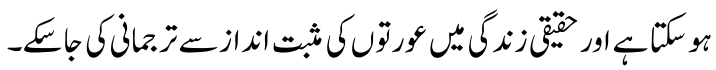




\section{Introduction}

Mass media not only gives information and instruction but also entertains certain values of the society. The media fully saturate the lives of general public in the social setup. Woman is an important part of the society where she has been considered less capable and portrayed as an inferior sex object on the media and victim of violence which takes place in house, work place or elsewhere and may lead to any psychological problem carrying her to the dark shadows of the world.

\section{Communication and Media}

A new idea, on media which is delivered to the society, simultaneously is a force with tremendous impact on today's world. Communication is a fundamental need of the mankind besides physical requirements of food and shelter.

(Lasswell, 1984) outlined three basic functions of communication;

I: The surveillance of environment.

II: The correlation of the parts of society in responding to the environment.

III: The transmission of the social heritage from one generation to the next. Mass media is used as a mean by individuals to connect them with others (or disconnect). (Aronson, 1995) ${ }^{1}$ listed 35 needs taken from the largely scattered literature on social and psychological functions of the mass media and put them into five categories;

1. Affective needs (pleasure, emotional or aesthetic experience)

2. Social integrative needs (strengthening contacts with family and friends)

3. Cognitive needs (acquiring information, knowledge and understanding)

4. Personal integrative needs (strengthening credibility, confidence, stability and status)

5. Tension release needs (escape and diversion)

\section{Role of Mass Media in the Society}

The influence of mass media on the society is incredible. It not only informs but also refine the attitude and opinion and tell the ways of analyzing the world around us and shape the behaviours.

Mass media generally play four main and fundamental functions in the society.

1. It informs the population in particular and in general.

2. It serves as the means of socializing the population in terms of attitude, values and behaviors.

3. It provides entertainment to all culture.

4. It behaves as an advocate of social change. 
The role of the mass media as an institution in the society can be classified into three categories.

1. As an agent of social change through its agenda setting functions.

2. As a reflector of dominant values.

3. As a reinforcer, it also strengthener the dominating values, models and attitudes in the society (council of Europe, 1984).

The charisma of television started spreading after World War II and it made its presence in every home. On average the television is watched over six hours a day in most of the homes. TV charisma grabbed the whole world very rapidly. Every medium has its own profile of cognitive advantages and disadvantages and each medium can be used to enhance the impact of others (Green field, 1984) ${ }^{2}$.

Each medium has its own message. The cognitive message of print is the opportunity for reflection. Print and Radio share the message of imagination, articulateness and serial processing .The message of television and film are an audio visual style of communication and still interpreting the two dimentional representation of movement and space.

Media has a considerable power to lead public opinion by virtue of its contents; media is able to shape the beliefs and attitudes of individuals (Noelle, 1981). ${ }^{3}$ The mass media can give audience ideas that may be then translated into open behavior (Berkowitz, 1964) ${ }^{4}$.

Jain noted that media is not only a passive channel reflecting dominant values but also works as an agency aiming at reinforcing rather strengthening the dominant value structure (Jain, 1997). This becomes possible by differentiating between the positive and negative values and elaborating do's and don'ts for the society.

Media not only inform us but also entertain us. It plays an important role in our daily life. It is very interesting to note that mass media not only sends message to the far distant places but many messages at a time simultaneously, so the electronic medium has been successful in achieving the results. The print medium engages all the audience at the same time and transmits the messages from generation to generation. Negating to television presentation and interesting visuals and audio combination is not easy.

Heeter reported that in general, television viewing is a more active pastime then radio listening (Heeter, 1988).

The medium of television provides a much welcomed, soothing alternative to the gaping voids of solitude and unstructured time. Mostly television views posses fewer inner 
resources to maintain emotional control balance and television provides that structure (Kubey, 1986). ${ }^{5}$

According to media researcher, "if I were to attempt to destroy a nation internally, I would brainwash that nation into accepting violence (Skornia, 1977) ${ }^{6}$. I would educate the masses to hate, kill, burn and destroy. I would condition people to tolerate violence as an acceptable type of behavior and condemn its use as the most effective means to solve problems. I would provide specific reason for the use of gun and knives and will show how cars can be used as instruments of death. I would present this information entertainingly on television".

\section{Projection of Women in Media}

Woman has been a topic of discussion since long, although she plays a tremendous role in the house and outside as well but still she is considered less capable and not task oriented as men. Most of the time women have been the victim of exploitation and discrimination and is being treated as an inferior gender.

"Women are largely been featured in T.V commercials in two capabilities as most solicited consumers and as instruments of persuasion“, noted by Jain that since 1970's women begun appearing in cooperative higher status jobs (Jain, 1997).

As Kamla Bhasin said," we are not just concerned with how women are portrayed in the media or how many women work in the media. We are also concerned about what kind of lives they lead, what status they have and what kind of society we have? The answers to these questions will determine our future strategies for communication and networks" (Bhasin, 1992).

In an exercise, women from 71 countries study their news on media for one day in January 1995. More than 15,500 stories were analyzed and the results were dramatic, only $17 \%$ of people interviewed in the news were women, just $11 \%$ of news stories dealt with the issues of special concern to women (Media Watch, 1995).

In one of the few extensive analysis of female imagery in the Arab States, Sarah Graham - Brown points out that, images of women may be used in conflicting ways, as symbols of progress on one hand and as symbols of continuity with the cultural past on the other. Frequently in the reaction to representation of women imposed from outside the society for instance by the western media, major ideological changes obviously affect the use of female imagery to promote national goal (Graham, 1988).

In the USA several studies of successful prime time series concluded that, "It articulates a new view of manhood but in reality it is substantially conservative (Hyde, 1995). ${ }^{7}$ 
It is noted by Margaret that "Overall media treatment of women can be best described as narrow. Women are rarely portrayed as rational, active or decisive underlying practically all media images is a dichotomous motif, which defines women as other perfectly good holy, evil, mother or whore, virgin or call girl, even traditional or modern" (Schuler, 1992).

Busby $(1975)^{8}$ and Durkin $(1985)^{9}$ provide comprehensive summaries of content analysis that focus on the portrayal of men and women on television, results indicated that,

1: Males are more often the stars of programmes.

2: Males are more often employed.

3: Females are more often stereotypical job, nurse and secretary.

4: Males are more often in the high status jobs.

5: Females are more often identified by their material status.

6: Females are usually young.

7: Married females who work are more likely to be unhappy.

8: Males are more violent.

9: Females are more often victims.

10: Females display more emotion.

11: Males are more often national, stable and powerful, Fernandez found that the dominant image is that of the sex given, the vamp and of women as concerned and primarily with gossip romantic fantasy, physical appearance and consumption (Fernandez, 1987). ${ }^{10}$

An analyzer of children programmes found that, "The girl and women were viewed as softer, weaker and more passive than boys and men (Welch, 1979) ${ }^{11}$ and boys were more autonomous, aggressive and inventive (Sternglanz, 1974). ${ }^{12}$

Women basically seen as performing decorative function and as being marginal to national development and growth. This results in a reinforcing of stereotype images.

The stereotypes have been identified as,

1: Women's place at home

2: The most important and valuable asset of women is physical beauty.

3: Women energies and intellect must be directed to guide and control men.

4: Women are dependant, coy, submissive

5: Good women are the traditional housewives.

It is generally noted that the stereotype images of women are never challenged so there is an evident increase in violence against women. Even in the children's cartoon, women are depicted as wagging, housewives, helpless in their relationship with males. 
In an article "Women should be portrayed in assertive roles on T.V" by Hajra Illahi published in the daily Dawn gave the findings of a survey report conducted by United Nations Development Program on the portrayal of women on media, indicating that now viewers need to match more gender balanced portrayal of women. It is desired that the negatively oriented and suppressed role of the women should not be displayed any more (Illahi, 2001).

The results of a survey on the projected role of men and women on PTV revealed that during $70 \%$ of the telecast time the viewers had perceived women as self sacrificing with no identity of their own. The working women are shown to be alienating their husbands and children for as much as $79 \%$ of the duration of the PTV plays. Professional women on average of $70 \%$ of the time are identified as fashion models, teachers and doctors, where as $90 \%$ of the time men are projected as politician, national heroes and high ranking government officials.

\section{Women and Society}

Media plays a fundamental role in shaping the opinions of the general public because of its strong influence. But it is observed that there has been a growing rate of violence against women since last few years .A recent report published in the Dawn (20 Dec 2006) prepared by an NGO presents the worst situation. It shows that in Pakistan more than 2500 women and 400 men were murdered in the name of honour killing (karo kari). Not less than two to three women were murdered for karo kari daily. More than 1200 women and 200 men were murdered in Sindh for karo kari, in Punjab 850 women and 107 men were murdered in the name of honour killing.

Punjab stands at number one after Sindh. It is quite evident to indicate that most of the women in Pakistan do not receive their due share in the properties. According to a survey conducted in Punjab in 1995 concluded that nearly two third of the households, daughters did not inherit land because it is customary for only sons to inherit. It is generally noticed that the victims of the violence are usually the women of the poor and middle class while the women of high society are not considered victims, so the most number of the victim women belong to weaker family background.

Human Rights Commission of Pakistan reported in 1997 that domestic violence remained a pervasive phenomenon. The supremacy of the male and subordination of female is assumed to be part of culture (HRCP, 1997). ${ }^{13}$

A comprehensive study by the United Nations says that the domestic violence is a structural rather than casual problem. The family structure is mirrored and confirmed in the structure of society which condones the oppression of women and tolerates male violence as one of the instruments in the perpetuation of this power balance. There is an 
alarming situation as $70 \%$ to $90 \%$ of women suffering from domestic violence in Pakistan.

In the majority of the cases husband and his family were responsible for violence and murders of the women. Honour killing is another recurrent form of familiar violence against women. The customary practice of killing women on suspected of an illicit liaison known as karo kari in Sindh and Baluchistan. The Sindh Government has reported an annual figure of 300 for such killings in which eighty six karo kari alone in Larkana, Sindh. Sexual assault is also an alarming cause of violence in Pakistan. HRCP estimated that in 1997 nearly eight women most of them minors were raped every twenty four hours nation wide.

\section{Violence, its Definition and Explanation}

Berger defines violence is a form of self assertiveness and aggressiveness and like most aggression is connected to frustration. Violence is a willful application of force in such a way that it is intentionally injurious to person or group against whom it is applied. Although the degree and form of violence may vary according to the class, region and culture (Berger, 1981). ${ }^{14}$

Aronson tried to distinguish between the behaviour that harms or does not harm others and applies the term aggression only to the behavior aimed at causing harm or pain (Aronson, 1995). ${ }^{15}$

Aggression is quite an uncertain defined term, there is no agreement on whether aggression is institutive as opposed to learned or not. It is said that human beings are innately brutal and aggressive and can only be constrained through society, law and order. An aggression is innate but also that is inherently good. It is an essential part of the life preserving organization of instructs. (Aronson 1995). ${ }^{16}$

An act of gender based violence that results in or is likely to result in physical, sexual or psychological harm or suffering to women including threats of such acts, arbitrary deprivation of liberty, whether occurring in public or private life. Accordingly violence against women encompasses but is not limited to the following. Physical, sexual and psychological violence occurring in the family including battering, sexual abuse of the female children in the household, dowry related violence, marital rape, and traditional harmful practices, non spousal violence etc. Other acts of violence against women include violation of human rights of women in situation of armed conflict in particular murder, systematic rape, sexual slavery and forced pregnancy. It is generally assumed that there are various forms of violence, but most commonly visible forms are verbal violence, symbolic violence, physical violence, sexual violence, situational violence and psychological violence. 


\section{Verbal Violence}

Many cultures have sayings or expressions that are considered harmless: there is a long tradition that teaches us to ignore verbal attacks. However, when these attacks become regular and systematic and purposefully target our sensitive attitudes (Source), the object of these attacks is right to consider themselves subjected to verbal abuse. Contrary to a functional relationship in which partners recognise each other's sensitive topics in time and take special care not to hurt, one who is verbally abusive will especially aim at hurting with words and tones.

Verbal abuse can include issues that are personal, such as making people feel of low esteem (in private or in front of others), ridiculing, the use of swear-words that are especially uncomfortable for other, abusing the loved ones of the other (family, friends), threatening with other forms of violence against the victim or against somebody or something dear to them. Verbal abuse is also related to the heritage of the victim, such as religion, culture, language, (perceived) sexual orientation or traditions. Depending on the most emotional, sensitive matters of the victim, abusers consciously target these issues in a way that is painful, humiliating and threatening to the victim.

\section{Psychological Violence}

Psychological violence has been defined in a number of ways over the years. Unlike physical and sexual violence, psychological violent act can range from the overt to subtle. (Pense \& Paymar, 1993) noted that certain programs such as domestic containment programmes in Duluth Minnesota have used the most inclusive definition that could be referred to a psychological abuse (. This definition is likely to include some men as batterers who in the past may have been labeled as abusive, unfair fights or chauvinist. Their power and control wheel describes eight forms of psychological abuse consisting of specific behaviors.

- Using coercion and threats (making and/or carrying out threats to do something to hurt her, threatening to leave her, to commit suicide, or to report her to welfare, making her denying drop charges, making her do illegal things)

- Using economic power (preventing her from getting or keeping a job,compelling her to ask for money, giving her an allowance, taking her money, not letting her know about or have access to family income)

- Using male privilege (treating her like a servant, making all the big decisions, acting like the master of the castle, being the one to define men and women's roles) 
- Using children (making her feel guilty about the children, using the children to convey messages, using visitation to harass her, threatening to take away the children)

- Minimizing, denying, and blaming (ignoring the abuse and not taking her concerns seriously, making her responsible for the abuse)

- Using isolation (controlling her activity, whom she meets and talks to, what she reads and where she goes, limiting her mobility, using jealousy to justify actions)

- Using emotional abuse (letting her down, making her a victim of inferiority complex, calling her names, making her think she's crazy, playing mind games, humiliating her, making her feel guilty)

- Using intimidation (making her afraid by using looks, actions, gestures, smashing things, destroying her property, abusing pets, displaying weapons)

\section{Symbolic Violence}

Symbolic violence includes actions that have discriminatory or injurious meaning or implications, such as gender dominance and racism. Symbolic violence maintains its effect through the mis-recognition of power relations situated in the social matrix of a given field.

Symbolic violence is fundamentally the imposition of categories of thought and perception upon dominated social agents who then take the social order to be just. It is the incorporation of unconscious structures that tend to perpetuate the structures of action of the dominant. The dominated then take their position to be "right." Symbolic violence is in some sense much more powerful than physical violence. It is embedded in the very modes of action and structures of cognition of individuals, and imposes the specter of legitimacy of the social order.

\section{Physical Violence}

Physical violence includes beating, burning, kicking, punching, biting, maiming or killing, the use of objects or weapons, or tearing out one's hair. Some classifications also include trafficking and slavery in the category of physical violence because initial coercion is often experienced, and the young women and men involved end up becoming victims of further violence as a result of their enslavement.

According to the Council of Europe, domestic violence is the major cause of death and disability for women aged 16 to 44 and accounts for more death and ill-health than cancer or traffic accidents (Parliament Assembly of the Council of Europe, 2002). Amnesty 
International quotes a Russian government estimate which states that ' 14,000 women were killed by their partners or relatives in 1999 (Amnesty International, 2004).

\section{Conclusion}

It can be concluded that the projection of women in media and portrayal of violence against them is of notable ratio and women are depicted in a passive role. It is very important to change the image of women through the mass media as it is assumed that T.V programmes play crucial role in removing the gender bias. It is now of vital importance that such gender bias should be eliminated at the levels of policy making, planning and selection of content and context of programmes. The ongoing communication revolution has opened up new possibilities of involvement of women as participant as well as beneficiaries. So, the mental, physical and conceptual image of women needs to be enhanced.

\section{End Notes}

${ }^{1}$ Aronson, E; (1995) The Social Animal, $7^{\text {th }}$ Edition,New York: W. H. Freeman and Co, p. 252-253, http://www.homeoffice.gov.uk/rds/pdfs04/hors276.pdf

${ }^{2}$ Greenfield, P.M(1984) Mind and Media, the Effects of Television, Video Games and Computers, Cambridge, Harvard University Press, pp.178-179.

3 Noelle-Noumann(1981) "Mass Media and Social Change in developed Socities" In E.Katz, T. Szeccsko (eds), Mass Media and Social Change, California, Sage Studies, p.139.

4 Berkowitz, L. (1964) "The Effects of Observing Violence" In Scientific American, 210(2), p. 35-41.

5 Kubey. R. W(1986) "Television Use in Everyday Life: Coping with Unstructured Time" In Journal of Communication 36(3), p. 108-123.

${ }^{6}$ Skornia, H.J.(1977) “ The Great American Teaching Machine.... Of Violence” Intellect, In Introduction to Mass Communication, (2 $2^{\text {nd }}$ Ed), p. 253. http://www.homeoffice.gov.uk/rds/pdfs04/hors276.pdf.

7 Hyde.M.J (1995) "Human Being and the Call of Technology" In J.T.Wood and R.B.Gregg(Eds), The Future of the Field, Crasskill,Nj, Hampton, pp 47-79.

8 Busby, L.J.(1975) "Sex Role Research on the Mass Media" In Journal of Communication, 25, pp.107-131. 
${ }^{9}$ Durkin, K.(1985) Television, Sex Roles and Children, Milton Keynes, Open University Press, pp 9-13.

${ }^{10}$ Fernandez, D.G.(1987) "Women in the Media in the Philipines: From Stereo-Type to Liberation” In Media Asia 14(4), pp. 183-193.

${ }^{11}$ Welch, R.L., Huston-Stain,A,Wright, J.C. and Phelal, R.(1979) "Subtle Sex-role Cues in Children's Commercials” In Journal of Communication, 29, pp. 202-209.

12 Sternglanz, S.H. and Serbin, L.A.(1974) “Sex Role Stereotyping in Children's Television Programmes” In Developmental Psychology, 10, pp. 710-715.

${ }^{13}$ HRCP (1997) Human Rights Commission Of Pakistan, State of Human Rights in 1996, Women's Ministry, Battered House Wives in Pakistan (Islamabad: Women's Ministry). p.130, httP://Students.usm.maine.edu/darcey/Link6.html.

14 Berger, A. A (1981) Television as an Instrument of Terror, New Brunwich, New Jersey, p.95.

${ }^{15}$ Aronson, op.cit, (1995), p. 250.

${ }^{16}$ Aronson, op. cit., (1995), pp. 252-253.

\section{References}

Amnesty International (2004) It's in Our Hands. Stop Violence Against Women, London, Amensty International Publications, http://www.amnesty.org/en/library/info/ACT77/001/2004

Aronson, E; (1995) The Social Animal, $7^{\text {th }}$ Edition,New York: W. H. Freeman and Co, http://www.homeoffice.gov.uk/rds/pdfs04/hors276.pdf

Bhasin, Kamla, (1992) Women and Communication Alternatives: Hope for the Next, New York, Oxford University Press.

Council of Europe (1984) "Equality between women and men" Proceedings of seminar On the Contribution of the Media to the Promotion of Equality between Women and Men, Strasbourg.

Graham-Brown, Sarah (1988) Images of Women: The Portrayal of Women in Photography of the Middle East 1860-1950, London, Quartet Books.

Heeter,C. And Cohan, E.(1988) Viewing Style Differences Radio and T.V., http://www.informaworld.com. 
Illahi, Hajra (2001) "Women Should be Portrayed in Assertive Roles on T.V" an article In Daily Dawn.

Jain,N. (1997) Patriarchy Status of Women and Role of Media, a Study of Media Role in Cultural Reproduction in India, Ph.D. Thesis, University of Jammu.

Lasswell.H.D (1984) "The Structure and Function of Communication in the Society" In L.Bryson(Ed) The Communication of Ideas, New York, Harper Row.

Media Watch (1995) Women's Participation in the News: Global Media Monitoring Project, Toronto, Media Watch.

Parliamentary Assembly of the Council of Europe (2002) Domestic Violence Against Women, Recommendation 1582, Adopted 27 September, 2002.

Pense, Ellen and Paymar, Michael (1993) Education Groups for Men who Batter: The Duluth Model, New York, Springer Publications.

Schuler, Margaret (1992 Eds.) Freedom from Violence: Women's Strategies from Around the World, New York, Pact.

Lubna Naz Karim is Co-operative teacher in the Department of Mass Communication, University of Karachi. 